\title{
Sir Karl Popper, swans, and the general practitioner
}

At age 50 years, Ron Berghmans had back pain, which despite visits to his general practitioner increased in severity. Eventually Ron referred himself to a neurologist and realised things were more serious than anyone first thought

\author{
Ron Berghmans lecturer ${ }^{1}$, Harry C Schouten professor ${ }^{2}$ \\ 'Department of Health, Ethics and Society, CAPHRI School for Public Health and Primary Care, Maastricht University, PO Box 616, 6200MD \\ Maastricht, Netherlands ; ${ }^{2}$ Department of Internal Medicine, University Hospital Maastricht, PO Box 5800, 6202 AZ Maastricht, Netherlands
}

This is one of a series of occasional articles by patients about their experiences that offer lessons to doctors. The $B M J$ welcomes contributions to the series. Please contact Peter Lapsley (plapsley@bmj.com) for guidance.

What is truth? And what is truth in the encounter between a patient and a general physician? Is truth always determined either from the "observer" or the "patient's" perspective and thus subjective? Or does something like objective truth exist? During my journey as a patient I experienced pain and emotional suffering. I did not worry about philosophical questions relating to truth in general or truth as it applies to medicine and the medical encounter. Questions relevant for the philosophy of science seem to be far removed from the sickbed and the delivery of professional medical care and treatment. But are they?

The most difficult part of my journey through the medical system was the entry. As a 50 year old I already had a history of low back pain. Around the time of my 50th birthday the pain increased. This was a reason to consult my general practitioner (GP). Quickly, and without physical examination, she was convinced that there was no reason to worry. She knew I was a busy academic who had a stressful working life with my research and teaching. Her advice was to try to reduce the stress as much as possible by not working too hard (in my patient file she noted: "functional, non-specific low back pain resulting from work stress"). Her advice didn't help. On the contrary, the back pain increased and a month later I consulted her again. This time she prescribed pain medication. This was of no avail either. I returned to see her again some weeks later and asked her to refer me for radiography. She was very reluctant to do this and explained the "dangers" of radiation. Only after much pressure did she agree. The radiographs of the lower parts of my back didn't show any major aberrations, although there were some minor abnormalities at the vertebrae. My GP seemed content to see these peculiarities as the possible (probable) causes of my pain. Nevertheless, my situation kept worsening. During the long nights I experienced severe pain; I would lie in bed in a separate room, howling like a wolf (as my wife said) and having involuntary contractions of my legs. It became more and more difficult to stand up and walk, and I lost the ability to stay upright.

In the Dutch healthcare system the GP has a gatekeeping role. This makes it difficult for patients to access specialised healthcare services without a referral from their GP. In my case my GP refused to refer me to a neurologist. As my medical condition kept worsening, I decided to make an appointment for a consultation with a neurologist in Belgium (where patients have the freedom to contact specialised healthcare staff independently). When I confronted my GP about this, she noted in my patient file: "It's the patient's wish, so be it. .." Ultimately, this neurologist referred me to the neurosurgery department, where an assistant decided to do magnetic resonance imaging of the whole of my back (not just the lower parts). These scans showed that cancerous tissue, which was all around my lungs and belly, was already pressing on my spinal cord. This explained the progressive and extreme pain I had been experiencing. Chemotherapy and autologous stem cell transplantation were successful.

Ten months had passed between my first encounter with my GP and the final diagnosis of non-Hodgkin lymphoma and it was only because a thoughtful neurosurgery assistant was willing to look beyond the lower back (on which the GP had focused) that the cancerous tissue became visible and the truth was revealed. I crossed the threshold and my journey as a cancer patient eventually started.

So what about the truth? Does it matter? Yes, it does. Looking back at my entry into the medical system, I came to realise the importance, indeed the lifesaving, potential of the work of the philosopher of science Sir Karl Popper. In particular, his views on truth are very relevant for medicine and GP's. My GP's way 
of approaching the truth would be abhorrent to Popper. By searching for confirmation of her initial diagnosis she found nothing but a truth that was already there. As Popper would say, if you suppose all swans are white, you will not find any swans than white swans. Popper's revolutionary insight was that you should, in fact, be searching for black swans. Only then will it be possible to gain better knowledge about the world and what happens in it. This so called falsification principle has had great impact on the philosophy of science and the way in which empirical scientific knowledge is achieved. Briefly, it involves the formulation of testable hypotheses (that is, predictions about what is the matter or what will happen) and the intention to falsify these expectations. Do not try to look for white swans, but instead look for black swans. Only this way, in Popper's view, can the truth be approached.

Subjectively, I think the course set by my GP (and continued by several of my specialists who based their actions on the information given by her) might have had serious if not fatal consequences for my health and existence. This is obviously an observation I cannot confirm or falsify but nevertheless does not seem unreasonable.

Doctors, and in particular GP's, should always bear in mind the fallibility of their assumptions. This is the central message Karl Popper has for the daily practice of medicine. When I typed "falsification+principle+medical +diagnosis" into Google it showed 223000 hits, but only a few bits of information were usable. One relevant piece was the Wikipedia entry "Confirmation bias" (http://en.wikipedia.org/wiki/Confirmation_ bias), which stated: "Confirmation bias (also called confirmatory bias or myside bias) is a tendency for people to favor information that confirms their preconceptions or hypotheses regardless of whether the information is true. As a result, people gather evidence and recall information from memory selectively, and interpret it in a biased way. The biases appear in particular for emotionally significant issues and for established beliefs." And with regards to physical and mental health Wikipedia stated: "Raymond Nickerson, a psychologist, blames confirmation bias for the ineffective medical procedures that were used for centuries before the arrival of scientific medicine. If a patient recovered, medical authorities counted the treatment as successful, rather than looking for alternative explanations such as that the disease had run its natural course." I found no links to information on confirmation bias with regards to medical diagnosis, treatment, or general physicians.

At no point during the process was my GP willing to reconsider her initial diagnosis, although my situation was progressively worsening and becoming unbearable. She was, and stayed, convinced that her truth was the truth-that I had "aspecific low back pain,"- and this preconception kept her away from considering any contrary evidence that would refute this preconception. She didn't look for black swans, all she saw were white swans.

My hypothesis is that in medical schools and education no, or insufficient, attention is being given to the philosophy of science in general, and Popper's theory in particular. Now it's time to try to refute this hypothesis, and make real progress in daily medical practice, for the sake of patients with complaints that appear to be clear, obvious, undeniable and easy to explain, but are not. This requires a transformation in the mindset of GP's and a fundamental willingness to try not to look for support for their convictions, but to search instead for alternative explanations for the complaints of patients.

Competing interests: All authors have completed the ICMJE uniform disclosure form at www.icmje.org/coi_disclosure.pdf (available on request from the corresponding author) and declare: no support from any organisation for the submitted work; no financial relationships with any organisations that might have an interest in the submitted work in the previous three years; no other relationships or activities that could appear to have influenced the submitted work.

Provenance and peer review: Not commissioned; not externally peer reviewed.

Groopman J. How doctors think. First Mariner Books, 2008

2 A predictive model for aggressive non-Hodgkin's lymphoma. The International Non-Hodgkin's Lymphoma Prognostic Factors Project. N Engl J Med 1993;329:987.

Accepted: 6 June 2011

Cite this as: BMJ 2011;343:d5469

(c) BMJ Publishing Group Ltd 2011 


\section{A clinician's perspective}

When you see a patient with a new complaint, your way of thinking may be influenced by previous encounters with this specific patient or, alternatively, by your experience with previous patients with similar complaints. Many times this may be very helpful for these patients and may spare them potentially dangerous diagnostic procedures. However, sometimes this biased personal experience may damage a patient, as described by Ron Berghmans.

Although we all know in this era of evidence based medicine that personal experience, or even expert opinion, is generally considered to be relatively weak evidence, we all run the risk posed by flawed first or second impressions. Readers doubting this really should read How Doctors Think by Jerome Groopman. ${ }^{1}$ This book teaches us to be very modest about our professional approach to individual patients' complaints and should stimulate us all to approach patients in an open way, designing a formal listing of differential diagnoses, based on likelihood of occurrence.

Being a haematologist working in a university hospital setting, I realise that I am rarely the first physician to see the patient. As in Ron's experience, it is generally the GP who considers a malignancy and requests a computed tomography scan, or a neurologist who raises the suspicion of a malignancy resulting in a referral to someone like me, who then can hardly miss the obvious diagnosis.

Large cell lymphoma is a disease originating from our developing immune system. The malignant tumour is generally very chemosensitive, and the combination of chemotherapy and a monoclonal antibody results in high response rates and a substantial subset of patients cured. Did the diagnostic delay harm Ron? We will never know. However, a diagnostic delay may result in a larger tumour burden, more extensive spread of the disease (higher stage or more extra nodal localisations), or development of the tumour to a more aggressive subtype (also associated with a higher level of lactate dehydrogenase), which are all characteristics of a poor prognosis, as shown by the international prognostic index. ${ }^{2}$ But this is only part of the problem. The fear and anxiety for a patient when their complaints are not taken seriously by their physicians can be devastating and result in loss of confidence in our healthcare providers and may influence compliance and perseverance. Or even worse, some patients may turn to alternative medicine, resulting in even more damage.

Especially in these days of limited financial budgets and high work load we all should try to spend healthcare money as appropriately as possible, without being biased by our opinions, first impressions, and budgetary constraints.

Harry C Schouten harry.schouten@mumc.nl 